\title{
Review: prokinetics and histamine-2 receptor antagonists improve symptom scores in non-ulcer dyspepsia
}

Soo S, Moayyedi P, Deeks J, et al. Pharmacological interventions for non-ulcer dyspepsia. Cochrane Database Syst Rev 2000;(2):CD001960 (latest version 22 Feb 2000).

QUESTION: In patients with non-ulcer dyspepsia, what is the relative effectiveness of 6 classes of drugs in improving symptom scores and quality of life?

\section{Data sources}

Studies were identified by searching the Cochrane Controlled Trials Register, Medline (1966 to 1999), EMBASE/Excerpta Medica (1988 to 1999), CINAHL (1982 to 1999), and SIGLE. Members of the Cochrane Upper Gastrointestinal and Pancreatic Diseases Group, experts in the field of dyspepsia, and pharmaceutical companies with an interest in gastroenterology were contacted for details of unpublished trials.

\section{Study selection}

Studies were selected if they were randomised controlled trials that included adult patients with dyspepsia symptoms and compared 1 of 6 drug classes (antacids, histamine-2 receptor antagonists $\left[\mathrm{H}_{2} \mathrm{RAs}\right]$, protonpump inhibitors, prokinetics, mucosal protection agents, and antimuscarinics) with placebo or a drug of a different class.

\section{Data extraction}

Data were extracted on patient characteristics, recruitment source, diagnostic criteria, dyspeptic symptoms, intervention and dosage, outcomes (dichotomous and continuous variables), and study quality.

\section{Main results}

57 trials were included. In comparisons with placebo, trials of prokinetics (12 trials), $\mathrm{H}_{2} \mathrm{RAs}$ (8 trials), and antimuscarinics (2 trials) showed improvement in dyspeptic symptoms with the active drugs (table). No other drug classes differed from placebo, irrespective of whether they were analysed as dichotomous or continuous variables. Trials with direct comparisons between prokinetics and $\mathrm{H}_{2} \mathrm{RAs}$, antacids and $\mathrm{H}_{2} \mathrm{RAs}$, and $\mathrm{H}_{2} \mathrm{RAs}$ and the antimuscarinic pirenzepine did not show statistically significant differences. Prokinetics and $\mathrm{H}_{2} \mathrm{RAs}$ were more effective than placebo in reducing individual dyspeptic symptoms. The prokinetics trials were considered most subject to potential publication bias.

\section{Conclusion}

In patients with non-ulcer dyspepsia, prokinetics and histamine-2 receptor antagonists are the most effective of 6 classes of drugs in improving symptom scores and quality of life.

\section{Sources of funding:} NHS Health

Technology Assessment Programme; Medical Research Council; NHS

Research and Development

Programme.

For correspondence: Dr S Soo, 30-32 Hyde Terrace, Leeds

LS2 9LN, UK. Fax $+44(0) 1132336778$

Drug classes vs placebo for improvement in dyspeptic symptom scores*

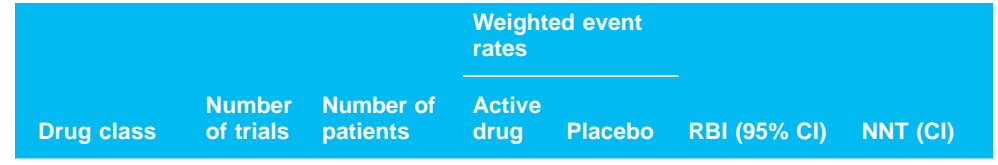

\begin{tabular}{lrrrrll} 
Prokineticst & 12 & 829 & $75 \%$ & $44 \%$ & $50 \%(30$ to 65$)$ & 4 (3 to 6$)$ \\
\hline $\mathrm{H}_{2} \mathrm{RAs}$ & 8 & 1225 & $71 \%$ & $51 \%$ & $30 \%(4$ to 48$)$ & 6 (5 to 9$)$ \\
\hline $\begin{array}{c}\text { Antimuscarinics } \\
\text { (pirenzepine) }\end{array}$ & 2 & 163 & $79 \%$ & $58 \%$ & $50 \%(19$ to 69$)$ & 5 (3 to 14$)$ \\
\hline
\end{tabular}

${ }^{*} \mathrm{H}_{2} \mathrm{RAs}=$ histamine-2 receptor antagonists. Treatment duration was 2 to 6 weeks for prokinetics and $\mathrm{H}_{2} \mathrm{RAs}$ and 4 weeks for pirenzepine. Other abbreviations defined in glossary; RBI, NNT, and $\mathrm{Cl}$ calculated from data in article.

+11 of the 12 prokinetics trials evaluated cisapride.

\section{COMMENTARY}

Dyspepsia is a common disorder with a prevalence of $20 \%$ to $50 \%$, more than half of which is non-ulcer dyspepsia. ${ }^{1}$ Clinicians must first determine whether endoscopic evaluation is indicated, then whether Helicobacter pylori status should be tested, and finally which treatment to offer.

A consensus panel described criteria for non-ulcer dyspepsia. ${ }^{2}$ However, non-ulcer dyspepsia is multifactorial, and differences in case definition not only account for much of the variability of prevalence estimates but also create heterogeneity among trials. These factors limit the confidence we can place in pooled estimates of effect.

Soo et al did a careful systematic review of data from 57 trials after excluding 50 studies that did not meet eligibility requirements and 37 eligible studies for which data extraction was not possible. They included trials in which case definition and outcome assessment methods were clear. This filter, although important for a meta-analysis, risks excluding potentially important studies. In fact, the authors caution that the prokinetic effect may be subject to publication bias and is therefore hard to interpret. ${ }^{3}$ They also warn that the quality of the $\mathrm{H}_{2} \mathrm{RA}$ studies was poor.

The findings show that $50 \%$ of patients get better on placebo, whereas $25 \%$ have persistent symptoms. Clearly, we need to understand better the underlying mechanisms of this disorder. Some patients improve dramatically with treatment, but typical patients require long term treatment. Until larger, long term, high quality trials are done, clinicians should continue to individualise treatment, searching for the most effective, safe, and economical choice over the long term.

Mark D Schwartz, MD New York University School of Medicine New York, New York, USA

1 Heading RC. Prevalence of upper gastrointestinal symptoms in the general population: a systematic review. Scand J Gastroenterol Suppl 1999;231:3-8.

2 Talley NJ, Stanghellini V, Heading RC, et al. Functional gastroduodenal disorders. Gut 1999;45 (suppl 2):II37-42.

3 Sutton AJ, Duval SJ, Tweedie RL, et al. Empirical assessment of effect of publication bias on meta-analyses. BMJ 2000;320:1574-7. 